\title{
ANATOMIA DO LENHO DE BERNARDIA PULCHELLA (EUPHORBIACEAE) ${ }^{1}$
}

\author{
ANELISE MARTA SIEGLOCH² JOSÉ NEWTON CARDOSO MARCHIORI ${ }^{3}$ \\ SIDINEI RODRIGUES DOS SANTOS ${ }^{4}$
}

\section{RESUMO}

A madeira de Bernardia pulchella apresenta, entre outros caracteres microscópicos: anéis de crescimento indistintos, porosidade difusa, placas de perfuração simples, pontoações intervasculares alternas, parênquima paratraqueal escasso, raios heterocelulares com menos de 3 células de largura, e fibras libriformes não septadas. Palavras-chave: Anatomia da Madeira, Bernardia pulchella, Euphorbiaceae.

\section{ABSTRACT \\ [Wood anatomy of Bernardia pulchella (Euphorbiaceae)].}

The wood of Bernardia pulchella presents, among other microscopic features: indistinct growth rings, diffuse porous wood, simple perforation plates, alternate intervascular pitting, scarce paratracheal parenchyma, heterocellular rays with less than three cells wide, and libriform non-septate fibres.

Key words: Bernardia pulchella, Euphorbiaceae, Wood Anatomy.

\section{INTRODUÇÃO}

De ampla distribuição geográfica e maior diversidade em regiões tropicais, a família Euphobiaceae reúne árvores, arbustos, ervas e lianas, por vezes suculentas e de aspecto cactóide (Judd et al. 2009). No Brasil, ela compreende cerca de 70 gêneros e 1.000 espécies, números que a incluem entre as mais numerosas da flora nativa (Souza \& Lorenzi, 2005). Sob o ponto de vista econômico, a família apresenta espécies valiosas, como a seringueira (Hevea brasiliensis), principal fonte de borracha natural, bem como espécies ricas em óleos (Aleurites molucana, A. fordii), ceras e gorduras vegetais (Judd et al. 2009), além de numerosas plantas de interesse ornamental.

Recebido para publicação em 14/10/2011 e aceito para publicação em 30/11/2011.

2 Engenheira Florestal formada pela Universidade Federal de Santa Maria. Santa Maria, RS, Brasil. anesiegloch@yahoo.com.br

3 Engenheiro Florestal, Dr. Bolsista de Produtividade em Pesquisa ( $\mathrm{CNPq}$ - Brasil). Professor Titular do Departamento de Ciências Florestais, Universidade Federal de Santa Maria. Santa Maria, RS, Brasil.

${ }^{4}$ Biólogo, doutorando do Programa de Pós-Graduação em Engenharia Florestal, UFSM.
A literatura dispõe de escassas referências sobre o gênero Bernardia P. Browne. Originária de Cuba, Bernardia dichotoma (Willd.) Müll. Arg. fornece madeira para pequenos artigos de tornearia e Bernardia microphylla (A. Rich) Müll. Arg. serve para caixotaria, segundo Record \& Hess (1943).

Objeto do presente estudo, Bernardia pulchella (Baill.) Müll. Arg. é o único representante lenhoso deste gênero na flora sul-brasileira e, vale salientar, ainda carece de maiores investigações no tocante a aspectos anatômicoestruturais do lenho. Arbusto de até $4 \mathrm{~m}$ de altura, apresenta tronco curto (até $15 \mathrm{~cm}$ de diâmetro), casca acinzentada e copa pequena, irregular. As folhas, lanceoladas (2-15 x 1,5-4 cm), com pecíolo de 1-6 mm e curtas estípulas, têm ápice acuminado, base cuneada, margens serreadas e nervuras pubescentes na face inferior; as flores, por suas vez, encontram-se em espigas (Marchiori, 2000). A espécie distribuise de Minas Gerais ao Paraguai, nordeste da Argentina e Rio Grande do Sul, habitando, neste Estado, tanto o interior como a orla das florestas Latifoliada e com Araucária (Rambo, 1960).

O presente trabalho, ao descrever a estrutura microscópica da madeira de Bernardia 
pulchella, visa a contribuir ao conhecimento botânico-estrutural da família Euphorbiaceae no sul do Brasil.

\section{REVISÃO DE LITERATURA}

A literatura oferece escassas referências sobre o xilema secundário de Bernardia pulchella. Em obra de caráter dendrológico, Marchiori (2000) inclui quatro fotomicrografias da madeira, salientando, para a mesma: poros em múltiplos radiais e racemiformes; raios finos, heterogêneos; vasos com pontoações alternas, placas de perfuração simples e espessamentos espiralados; e parênquima paratraqueal, com pontoações grandes, em arranjo escalariforme.

Hayden \& Hayden (2000), em estudo anatômico de 51 gêneros, pertencentes a 19 tribos de Alcalyphoideae, indicaram as seguintes características gerais para esta subfamília: anéis de crescimento indistintos ou fracamente definidos; poros bem distribuídos; placas de perfuração simples, não raro com mistura de placas irregulares e escalariformes; pontoações intervasculares alternas, pontoações raiovasculares circulares, alongadas e irregulares, maiores do que as intervasculares; parênquima axial difuso, difuso-em-agregados, e paratraqueal escasso, por vezes em faixas tangenciais; raios heterocelulares, raramente com mais de três células de largura; cristais prismáticos presentes no parênquima e/ou células de raios; e fibras de paredes finas a moderadamente espessas, não septadas, do tipo libriforme ou fibrotraqueóide. Para o gênero Bernardia, os autores referem, apenas, a ocorrência de placas de perfuração mistas (simples e escalariformes), de raios unisseriados ou predominantemente unisseriados, com células disjuntas, de fibras libriformes e ausência de cristais.

Metcalfe \& Chalk (1972), por sua vez, incluíram Bernardia no grupo das Crotonoideae, com base nas seguintes características: placas de perfuração simples; pontoações intervasculares médias a grandes; pontoações raiovasculares grandes e alongadas (frequentemen- te escalariformes) ou semelhantes às intervasculares; elementos vasculares de comprimento médio a moderadamente curto; parênquima abundante, apotraqueal, com células esparsas ou faixas contínuas de 1-2 células de largura; séries parenquimáticas de 8 células; raios com 2-3 células de largura ou exclusivamente unisseriados, por vezes com 4-5 células de largura; raios marcadamente heterogêneos, frequentemente com 10 ou mais fileiras marginais de células eretas e mais de 1 parte multisseriada por raio, por vezes com espaços intercelulares; fibras de paredes finas a moderadamente espessas, de comprimento médio a moderadamente curto, com pontoações simples ou aréolas pequenas; e tubos laticíferos ocasionais, nos raios.

Outras obras de interesse sobre a estrutura anatômica do lenho de Euforbiáceas podem ser encontradas em Record \& Hess (1943), Barros et al. (1997), Barros et al. (2001), Barros et al. (2003), Marchiori et al.(2009), Marchiori et al.(2011).

\section{MATERIAL E MÉTODOS}

O material em estudo consiste de uma amostra de madeira e respectivo material botânico, incorporados ao Herbário HDCF sob n 3192 , com as seguintes informações: J.N.C. Marchiori, n. 881, 23-07-1987, Gruta Linha 1, Jaguari, Rio Grande do Sul.

Para a descrição anatômica da madeira foram confeccionadas lâminas histológicas e de macerado. No primeiro caso, foram preparados três corpos-de-prova, orientados para a obtenção de cortes anatômicos nos planos transversal, longitudinal radial e longitudinal tangencial. O material lenhoso foi amolecido por fervura em água e seccionado em micrótomo de deslize, regulado na espessura de corte de $20 \mu \mathrm{m}$. Os cortes anatômicos foram tingidos com acridina-vermelha, crisoidina e azul-de-astra (Dujardin,1964), desidratados em série alcoólica-ascendente $(30 \%, 50 \%, 70 \%, 95 \%$, duas vezes em álcool absoluto) e, após passagem por xilol, foram montados em lâminas permanen- 
tes, usando-se "Entellan" como meio-de-montagem. Para as lâminas de macerado, seguiu-se o método de Jeffrey (Burger \& Richter, 1991) e coloração da pasta com safranina $1 \%$.

A descrição microscópica da madeira seguiu as normas do IAWA Committee (1989). Para as percentagens de tecidos usou-se um contador de células e 600 determinações ao acaso, de acordo com Marchiori (1980). A freqüência de poros $/ \mathrm{mm}^{2}$ foi obtida de forma indireta, a partir de um quadrado de área conhecida superposto a fotomicrografia de secção transversal da madeira. As medições foram realizadas no Laboratório de Anatomia da Madeira, com microscópio Carl Zeiss, dotado de ocular com escala graduada. Nas características quantitativas, os números entre parênteses equivalem aos valores mínimos e máximos observados; o valor que acompanha a média é o desvio padrão. As fotomicrografias foram tomadas em microscópio Olympus cx 40, com câmera digital Olympus Camedia c3000 acoplada ao microscópio, no Laboratório de Anatomia da Madeira da Universidade Federal do Paraná, a quem os autores agradecem.

\section{DESCRIÇÃO ANATÔMICA}

Madeira de porosidade difusa. Anéis de crescimento indistintos (Figura 1A,B).

Vasos: muito numerosos $(150,5 \pm 16,6$ (118 - 162) poros $/ \mathrm{mm}^{2}$ ), ocupando $18,8 \pm 2,2 \%$ do volume da madeira. Poros em múltiplos radiais de 13 (7-26) células e em múltiplos racemiformes de seção angular/poligonal; pequenos $(46 \pm 5(37,5-52,5) \mu \mathrm{m})$ e de paredes finas $(2,8 \pm(2,5-3,7) \mu \mathrm{m})$ (Figura 1A,B). Elementos vasculares de comprimento médio (567 $\pm 110(240-750) \mu \mathrm{m})$, com placas de perfuração simples (Figura 1D), ligeiramente oblíquas, e apêndices geralmente em uma extremidade. Pontoações intervasculares grandes $(12 \pm 0,8$ $(11,3$ - 13,4$) \mu \mathrm{m})$, alternas, circulares, não ornamentadas, com abertura em fenda inclusa (Figura 1F). Pontoações raio-vasculares com aréolas distintas, alternas, circulares até ovais, por vezes alongadas e semelhantes às intervasculares, embora menores $(8,8 \pm 0,5(8,2$ -9,3) $\mu \mathrm{m})$. Espessamentos espiralados, presentes (Figura 1D). Conteúdo, ausente.

Parênquima axial: representando $5 \pm 1,6 \%$ do volume da madeira; em arranjo paratraqueal escasso (Figura 1A,B). Séries parenquimáticas de $431 \pm 130(262,5-737,5) \mu \mathrm{m}$ de altura, compostas de $4(2-5)$ células (Figura 1E,F).

Raios: muito numerosos $(23 \pm 3,6(16-28)$ raios $/ \mathrm{mm}$ ), com 1 - 3 células de largura, ocupando $22,3 \pm 4,2 \%$ do volume da madeira (Figura 1E,F). Os multisseriados, de $167 \pm 60,8$ (60 - 290) $\mu \mathrm{m}$ e 5 (2-8) células de altura, com 2-8 células marginais; heterocelulares, reúnem, geralmente, células quadradas no corpo e células eretas nas margens (Figura $1 \mathrm{C}, \mathrm{E}, \mathrm{F})$. Os unisseriados, de 840,4 $\pm 308(350-1340) \mu \mathrm{m} \mathrm{e}$ 6 - 29 células de altura, são geralmente compostos de células eretas. Células radiais de paredes disjuntas e células perfuradas, presentes (Figura 1C). Raios fusionados, frequientes. Raios agregados, raros (Figura 1E). Células envolventes e conteúdos, ausentes.

Fibras: com pontoações menores do que 3 $\mu \mathrm{m}$, presentes nas faces radiais da parede; de comprimento médio $(909 \pm 112(660-1070)$ $\mu \mathrm{m})$, com 15,5 $\pm 2(12,5-20) \mu \mathrm{m}$ de diâmetro e de paredes finas a espessas 4,3 $\pm 0,7(2,5-$ $5,6) \mu \mathrm{m}$, ocupando $54 \pm 3,8 \%$ do volume da madeira (Figura 1B). Fibras gelatinosas, abundantes (Figura 1A,B). Espessamentos espiralados, fibras septadas e traqueóides, ausentes.

Outros caracteres: variantes cambiais, tubos laticíferos e taníferos, canais intercelulares, células oleíferas, células mucilaginosas, estratificação, máculas medulares e inclusões minerais, ausentes.

\section{ANÁLISE DA ESTRUTURA ANATÔMICA}

As características anatômicas observadas na madeira de Bernardia pulchella correspondem ao descrito por Hayden \& Hayden (2000) para a subfamília Alcalyphoideae: anéis de crescimento indistintos; poros bem distribuídos; placas de perfurações simples; pontoações 

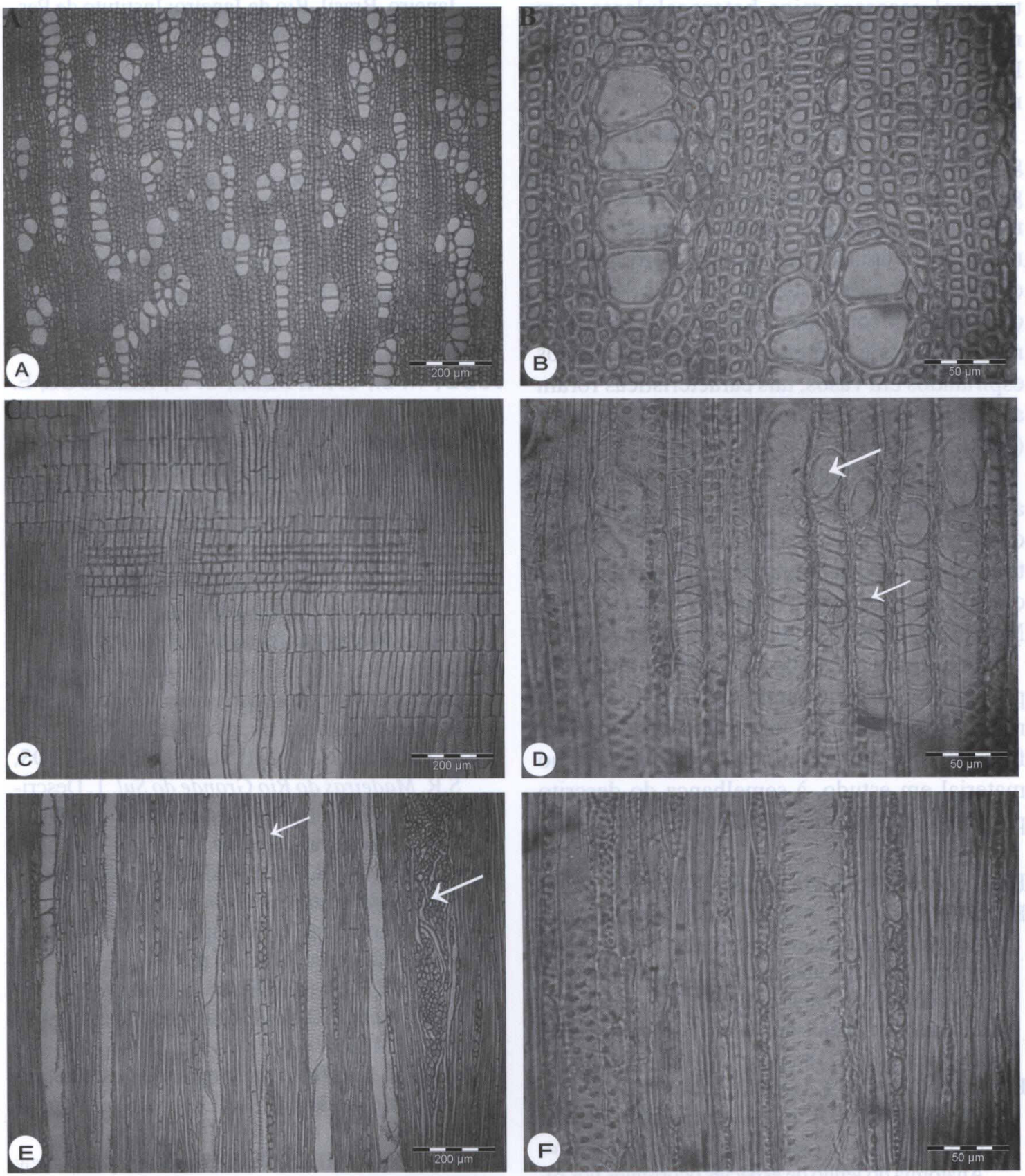

FIGURA 1 - Aspectos anatômicos da madeira de Bernardia pulchella. A - Seção transversal, mostrando poros em múltiplos radiais e racemiformes. B - Mesma seção, em maior aumento, com poros em múltiplos radiais e racemiformes, parênquima paratraqueal escasso e fibras de paredes finas a espessas. C - Raios heterogêneos, em seção longitudinal radial, com células quadradas no corpo central e células eretas nas margens. D - Seção longitudinal radial, em maior aumento, mostrando placas de perfurações simples (seta maior) e espessamentos espiralados (seta menor). E - Vista geral da seção longitudinal tangencial, com destaque para raios agregados (seta maior), parênquima axial (seta menor), vasos e raios uni e multisseriados. F - Vasos com pontoações intervasculares alternas, circulares ou ligeiramente poligonais, e raios uni e bisseriados (seção longitudinal tangencial). 
intervasculares alternas; parênquima paratraqueal escasso; raios heterocelulares com menos de 3 células de largura; e fibras libriformes não septadas, de paredes finas a moderadamente espessas.

A presença de pontoações intervasculares grandes, de pontoações raiovasculares alongadas, semelhantes às intervasculares, de elementos vasculares e fibras de comprimento médio, com pontoações simples, corroboram o descrito Metcalfe \& Chalk (1972). Com relação aos poros em múltiplos radiais e racemiformes e à presença de espessamentos espiralados em vasos, tais características foram anteriormente relacionadas por Marchiori (2000).

Metcalfe \& Chalk (1972) ainda mencionam a ocorrência de parênquima apotraqueal abundante para o gênero; no caso da espécie em estudo, todavia, o parênquima é paratraqueal escasso, concordando com o descrito por Marchiori (2000) e Hayden \& Hayden (2000).

A espécie em estudo não apresenta cristais prismáticos, tanto no parênquima axial como em raios. A presença de tubos lactíferos, caráter frequente na subfamília, não foi observada no material em estudo, à semelhança do descrito por Hayden \& Hayden (2000).

\section{REFERÊNCIAS BIBLIOGRÁFICAS}

BARROS,C.F.; CALLADO, C.H. Madeiras da Mata Atlântica. Anatomia do lenho de espécies ocorrentes nos remanescentes florestais do estado do Rio de Janeiro, Brasil. Rio de Janeiro: Instituto de Pesquisas Jardim Botânico do Rio de Janeiro, 1997. 86 p.

BARROS,C.F.; CALLADO, C.H.; MARCON M.L.; COSTA, C.G. CUNHA, M.; LIMA, H.R.P.; MARQUETE, O. Madeiras da Mata Atlântica. Anatomia do lenho de espécies ocorrentes nos remanescentes florestais do estado do Rio de Janeiro, Brasil. Rio de Janeiro: Instituto de Pesquisas Jardim Botânico do Rio de Janeiro, 2001. 94 p.

BARROS,C.F.; CALLADO, C.H.; CUNHA, M.; MARCON M.L.F.; TAMAIO, N; MARQUETE, O. COSTA, C. G. Madeiras da Mata Atlântica. Anatomia do lenho de espécies ocorrentes nos remanescentes florestais do estado do Rio de Janeiro, Brasil. Rio de Janeiro: Instituto de Pesquisas Jardim Botânico do Rio de Janeiro, 2003. $86 \mathrm{p}$.

BURGER, L.M., RICHTER, H.G. Anatomia da Madeira. São Paulo: Ed. Nobel, 1991. 154 p.

DUJARDIN, E.P. Eine neue Holz-Zellulosenfaerbung. Mikrokosmos, n. 53, p. 94, 1964.

HAYDEN, W. J.; HAYDEN, S. M. Wood anatomy of Alcalyphoideae (Euphorbiaceae). IAWA Bulletin, v. 20, n. 3, p. 213-235, 2000.

IAWA COMMITTEE. IAWA list of microscopic features for hardwood identification. IAWA Bulletin, v.10, n. 3, p. 218-359, 1989.

JUDD, W. S.; CAMPBELL, C. S.; KELLOGG, E. A.; STEVENS, P. F.; DONOGHUE, M. J. Sistemática vegetal: um enfoque filogenético. Porto Alegre: Artmed, 2009. p. 355-359.

MARCHIORI, J. N. C. Estudo anatômico do xilema secundário de algumas espécies dos gêneros Acacia e Mimosa, nativas no Estado do Rio Grande do Sul. 1980. 186f. Dissertação (Mestrado em Engenharia Florestal) - Universidade Federal do Paraná, Curitiba, 1980.

MARCHIORI, J. N. C. Dendrologia das angiospermas: das Bixáceas às Rosáceas. Santa Maria: Editoraufsm, p. 139-177, 2000.

MARCHIORI, J.N.C.; MUÑIZ, G.I.B.; SANTOS, S.R. Madeiras do Rio Grande do Sul. 1. Descrição microscópica de 33 espécies nativas. Santa Maria: Anaterra, 2009. 80 p.

MARCHIORI, J.N.C.;DENARDI, L.; SANTOS, S.R. Madeiras do Rio Grande do Sul. 3. Descrição microscópica de 34 espécies nativas. Santa Maria: Anaterra, 2011.80 p.

METCALFE, C.R.; CHALK, L. Anatomy of the Dicotyledons. Oxford: Clarendon Press, 1972. p. 1207-1235.

RAMBO, B. Euforbiáceas riograndenses. Pesquisas, Série Botânica, São Leopoldo, n. 9, p. 178, 1960.

RECORD, S.J.; HESS, R.W. Timbers of the New World. New Haven: Yale University Press, 1949. $640 \mathrm{p}$.

SOUZA, V.C.; LORENZI, H. Botânica Sistemáti$c a$ : guia ilustrado para identificação das famílias de Angiospermas da flora brasileira, baseado em APG II. Nova Odessa: Instituto Plantarum, 2005. 640 p. 